\title{
MEDIA PEMBELAJARAN BERBASIS MOTION GRAPHIC SEBAGAI ALTERNATIF MATERI MESIN ESEC 3088 UNTUK TEKNIK MANUFAKTUR ELEKTRONIKA POLITEKNIK NEGERI BATAM
}

\author{
Pragus Ilham Nayomi ${ }^{1}$, Arta Uly Siahaan ${ }^{2}$ \\ Informatics Engineering, Batam State Polytechnic \\ Multimedia and Network Engineering, Batam State Polytechnic \\ pragus238@gmail.com 1 , artauly@ polibatam.ac.id ${ }^{2}$
}

\begin{tabular}{l} 
Article Info \\
Article history: \\
Received Sept $12^{\text {th }}, 2021$ \\
Revised Nov $20^{\text {th }}, 2021$ \\
Accepted Nov $10^{\text {th }}, 2021$ \\
\hline
\end{tabular}

\section{Keyword:}

Motion Graphic

Mesin ESEC 3088

Villamil-Molina

\begin{abstract}
ABSTRAK
Motion graphic yang dibuat adalah tentang mesin ESEC 3088 yang digunakan sebagai mesin pengemasan rangkaian atau yang biasa disebut IC Packaging. Selama ini mahasiswa dan dosen Teknik Manufaktur Elektronika hanya menggunakan materi dari mesin ESEC 3088 dalam bentuk pdf dan word yang didapat dari e-learning. Dari masalah tersebut, penulis membuat sebuah penelitian "Media Pembelajaran Berbasis Motion Graphic Sebagai Alternatif Materi Mesin ESEC 3088 untuk Teknik Manufaktur Elektronika Politeknik Negeri Batam ", yang bertujuan sebagai media alternatif pembelajaran yang mempermudah para mahasiswa dalam mempelajari tata cara penggunaan mesin ESEC 3088. Metode penelitian yang digunakan adalah metode pengembangan multimedia milik Villamil-Molina dengan menggunakan metode pre-test dan post-test, untuk menilai tingkat pemahaman mahasiswa terhadap materi yang disampaikan pada motion graphic. Hasil dari penelitian ini adalah hasil dari nilai uji post-test yang lebih tinggi dibandingkan dengan nilai pre-test yang berarti motion graphic yang dibuat oleh peneliti berhasil meningkatkan tingkat pemahaman mahasiswa terhadap materi yang disampaikan.
\end{abstract}

\section{PENDAHULUAN}

Pembelajaran bisa dikatakan sebagai salah satu elemen dari pendidikan, salah satunya adalah pendidikan vokasi. Pendidikan vokasi adalah sistem pendidikan tinggi yang diarahkan pada penguasaan keahlian terapan tertentu kepada peserta didik dalam rangka mencapai tujuan pendidikan (Lenterakecil, 2018). Pendidikan vokasi merupakan pendidikan tinggi yang ditujukan untuk kepentingan praktis melalui program pendidikan diploma I (D1), diploma II (D2), diploma III (D3), diploma IV (D4) atau sarjana terapan, Magister Terapan dan Doktor Terapan. Lembaga pendidikan tinggi keahlian terapan (vokasi) adalah Universitas yang menyelenggarakan program diploma, akademi, Politeknik, Sekolah Tinggi, Institut dengan waktu studi untuk program diploma I selama 1 tahun, diploma II selama 2 tahun, diploma III selama 3 tahun, dan diploma IV selama 4 tahun. Standar nasional pendidikan vokasi dikembangkan berdasarkan standar kompetensi nasional atau internasional.

Di era perkembangan teknologi yang semakin maju, teknologi informasi dan komunikasi mempunyai peran penting dalam membuat sebuah media pembelajaran sebagai penunjang pembelajaran dan materi dalam dunia pendidikan baik dari sekolah dasar hingga perguruan tinggi. Dalam menerapkan pembelajaran, pengajar dapat menggunakan berbagai media pembelajaran sebagai pendukung dalam melakukan proses pembelajaran, salah satunya adalah motion graphic. Motion graphic merupakan potongan-potongan visual berbasis waktu yang menggabungkan unsur film dan desain grafis. Hal tersebut bisa dicapai dengan menggunakan berbagai 
jenis dari elemen seperti animasi 2D atau 3D, videografi, film, tipografi, ilustrasi, fotografi dan juga musik (Sukarno, 2008).

Pembelajaran yang akan dibuat adalah materi untuk mesin ESEC 3088, mesin ESEC 3088 tersebut memiliki bagian mesin atau part yang sangat banyak, tata cara penggunaan mesin ESEC 3088 juga sangat rumit, sehingga dapat menyulitkan para mahasiswa dalam mempelajarinya. Hal ini yang membuat penulis untuk membuat tugas akhir "Media Pembelajaran Berbasis Motion Graphic Sebagai Alternatif Materi Mesin ESEC 3088 Untuk Teknik Manufaktur Elektronika Politeknik Negeri Batam” agar mempermudah mahasiswa dalam pembelajaran. Media pembelajaran dalam bentuk motion graphic ini ditujukan kepada mahasiswa D-3 Teknik Manufaktur Elektronika dan dosen pengajar di TFME Polibatam.

Motion graphic yang dibuat adalah tentang mesin ESEC 3088 yang digunakan sebagai mesin pengemasan rangkaian atau yang biasa disebut IC Packaging. Selama ini mahasiswa dan dosen Teknik Manufaktur Elektronika hanya menggunakan materi dari mesin ESEC 3088 dalam bentuk pdf dan word yang didapat dari e-learning. Materi pembelajaran dalam bentuk pdf atau word ini memiliki kelebihan dan juga kekurangan. Kelebihan materi pembelajaran dalam bentuk pdf atau word yaitu, dapat menyajikan materi dalam jumlah yang banyak, dapat dipelajari oleh para mahasiswa sesuai dengan kebutuhan, dapat dipelajari kapan dan dimana saja karena mudah untuk diakses melalui e-learning. Sedangkan kekurangan menggunakan materi pembelajaran dalam bentuk pdf atau word yaitu, proses pembuatannya membutuhkan waktu yang lama, dari wawancara formal yang penulis lakukakn kepada dosen pengajar dan juga mahasiswa Teknik Menufaktur Elektronika, didapatkan informasi tentang materi pembelajaran yang berformat pdf atau word dapat membuat mahasiswa yang membaca menjadi bosan karena materi berisi teks yang mendominasi dan dapat menghilangkan minat untuk membacanya.

Dari masalah tersebut, penulis membuat sebuah penelitian "Media Pembelajaran Berbasis Motion Graphic Sebagai Alternatif Materi Mesin ESEC 3088 Untuk Teknik Manufaktur Elektronika Politeknik Negeri Batam ", yang bertujuan sebagai media alternatif pembelajaran yang mempermudah para mahasiswa dalam mempelajari tata cara penggunaan mesin ESEC 3088, diharapkan dengan adanya media pembelajaran dalam bentuk motion graphic ini dapat meningkatkan pembelajaran serta wawasan para mahasiwa dalam mempelajari mesin ESEC 3088 tersebut.

\section{ANALISIS DAN PERANCANGAN}

\subsection{Metode Perancangan} 5 tahapan.

Metode perancangan yang diterapkan adalah metode pengembangan Villamil-Molina yang meliputi

1. Development

Tahapan ini membahas tentang konsep aplikasi multimedia berdasarkan dari ide, tujuan, dan sasaran yang sudah ada.

a. Pembentukan Ide

Perencanaan ide dan isi dari motion graphic ini adalah pengenalan dan kegunaan dari mesin ESEC 3088 sebagai mesin tipe IC Packaging.

b. Tujuan Pencapaian

Tujuan yang ingin dicapai adalah dihasilkannya motion graphic sebagai media pembelajaran bagi Teknik Manufaktur Elektronika Politeknik Negeri Batam, sebagai tunjangan materi untuk mesin ESEC 3088 guna mempermudah proses perkuliahan bagi para mahasiswa.

c. Sasaran

Target audience dari motion graphic ini adalah mahasiswa dan dosen Teknik Manufaktur Elektronika.

2. Preproduction

Tahap preproduction adalah riset terhadap konten, mengembangkan garis besar dari motion graphic yang dibuat, desain objek, naskah atau script, storyboard, rekaman audio atau dubbing, pemilihan backsound, dan persiapan hardware dan software.

a. Desain Sketsa Mesin 
Pembuatan sketsa dari mesin ESEC 3088 atau wire bonding. Gambar 1 merupakan desain sketsa mesin ESEC 3088.

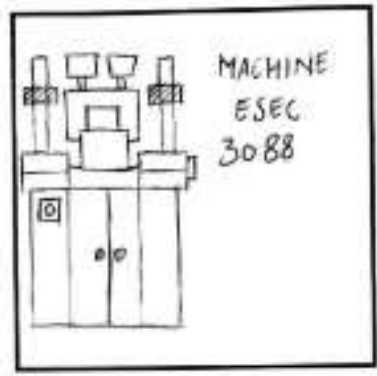

Gambar 1 Desain Sketsa Mesin

b. Desain Objek dan Logo

Pembuatan desain sketsa kasar yang nantinya akan dibutuhkan dalam melengkapi konten-konten yang terdapat dalam motion graphic berupa logo, maupun background.

c. Naskah

Pembuatan naskah motion graphic mesin ESEC 3088 ini berisikan alur atau jalan cerita dan juga narasi dalam motion graphic.

d. Storyboard

Storyboard merupakan sebuah sketsa gambar yang tersusun secara berurutan sesuai dengan naskah.

e. Spesifikasi dan Persiapan Hardware dan Software

Pada proses perancangan pembuatan karya multimedia dibutuhkan spesifikasi hardware dan software yang akan digunakan. Spesifikasi hardware dan software dapat dilihat pada Tabel 1.

Tabel 1 Spesifikasi Hardware dan Software

\begin{tabular}{|l|l|}
\hline Perangkat & \multicolumn{1}{|c|}{ Keterangan } \\
\hline \multirow{5}{*}{ Hardware } & - Laptop \\
& - RAM 8 GB \\
& - VGA Nvidia GeForce 850 \\
& - Speaker \\
& - Microfon \\
& - Flashdisk Sandisk 16 GB \\
& - Harddisk Trandscend ext 1 TB \\
\hline \multirow{5}{*}{ Software } & - Windows 10 \\
& - Adobe After Effect CC 2019 \\
& - Adobe Photoshop CC 2019 \\
& - Adobe Illustrator CC 2019 \\
& - Adobe Premiere CC 2019 \\
& - VLC Media Player \\
\hline
\end{tabular}

3. Production

Tahap akan dimulainya pembuatan motion graphic mesin ESEC 3088. Dimulai dari tracing menggunakan Adobe Illustrator CC 2019, melakukan animating motion graphic menggunakan software Adobe After Effect CC 2019, proses compositing motion graphic dengan dubbing dan backsound serta rendering menggunakan Adobe Premiere CC.

4. Postproduction

Pada tahap ini produk multimedia memasuki pengujian alpha dan beta testing. Pengujian alpha akan dilakukan oleh tim pengembang atau validator, dalam pembuatan motion graphic ini terdiri dari 2 tim pengembang yaitu validator materi dan validator media.

a. Validator Materi 
Pengujian yang melibatkan validator materi berfungsi untuk mengetahui tingkat kelayakan motion graphic dari segi informasi, kesesuaian materi, bagian dan part dari mesin ESEC 3088 yang terdapat didalamnya, pengujian ini dilakukan oleh tim internal TFME Politeknik Negeri Batam.

b. Validator Media

Pengujian yang melibatkan validator media berfungsi untuk mengetahui tingkat kelayakan motion graphic dari segi unsur-unsur media yang ada didalamnya. Pengujian alpha testing yang dilakukan oleh validator media memiliki aspek yaitu aspek tampilan dan penyajian serta kisi-kisi instrumen mengenai unsur-unsur media pada motion graphic. Setelah tahap pengujian alpha testing dilakukan dan produk telah selesai dievaluasi maka penulis melanjutkan tahap pengujian selanjutnya yaitu tahap beta testing. Beta testing merupakan tahapan pengujian akhir produk sebelum produk dapat dikemas dalam dalam bentuk CD/DVD maupun bentuk lainya. Tahapan yang dilakukan saat tahap pengujian beta testing hampir sama dengan alpha testing akan tetapi ada satu hal yang membedakan kedua tahapan pengujian tersebut yaitu ruang lingkup pengujian tersebut dilakukan.

Setelah data dari validator materi dan validator media terkumpul, maka data akan dianalisis menggunakan Analisis Kevalidan. Setiap validator akan diberikan validasi melalui google form untuk diisi, validasi tersebut akan dihitung menggunakan skala likert $1-5$ seperti berikut :

Skor 1 : Tidak Valid

Skor 2 : Kurang Valid

Skor 3 : Cukup Valid

Skor 4 : Valid

Skor 5 : Sangat Valid

Data validasi dari para validator tersebut dianalisis dengan mempertimbangkan kritik atau saran dari para ahli. Hasil analisis tersebut dijadikan pedoman untuk merevisi produk. Teknik analisis data validitas berasal dari hasil penyebaran kuisioner kepada para validator materi dan media akan dicari persentasenya. Gambar 2 merupakan rumus persentase analisis kevadilan.

$$
\text { presentase }=\frac{\sum \text { skor per item }}{\text { skar maksimum }} \times 100 \%
$$

Gambar 2 Rumus Persentase Analisi Kevadilan

Berdasarkan hasil presentase kemudian dikatergorikan sesuai dengan tabel berikut. Tabel 2 merupakan kategori validasi.

Tabel 2 Kategori Validasi

\begin{tabular}{|c|c|}
\hline$\%$ & Kategori \\
\hline $0-20$ & Tidak Valid \\
\hline $21-40$ & Kurang Valid \\
\hline $41-60$ & Cukup Valid \\
\hline $61-80$ & Valid \\
\hline $81-100$ & Sangat Valid \\
\hline
\end{tabular}

5. Delivery

Tahapan ini adalah akhir dari proses pengembangan multimedia versi Villamil-Molina. Pada tahap ini menggunakan beberapa cara yaitu, presentasi baik individu ataupun kelompok melalui tatap muka atau internet.

\subsection{Perancangan Analisis}

Pada rencana analisis, peneliti akan memberikan mahasiswa Teknik Manufaktur Elektronika pre-test dan post-test. Pre-test dan post-test ini dilakukan untuk menganalisa tingkat pemahaman mahasiswa kelas regular Teknik Manufaktur Elektronika sebelum dan sudah menonton motion graphic dari materi mesin ESEC 
3088. Pre-test merupakan bentuk pertanyaan yang diberikan sebelum proses pembelajaran dimulai, sedangkan post-test merupakan bentuk pertanyaan yang diberikan setelah pembelajaran dimulai (Sukri, 2018).

Pre-test yang diberikan berupa pertanyaan tentang pengetahuan mahasiswa terhadap mesin ESEC 3088 untuk menilai kemampuan awal mahasiswa sebelum menonton motion graphic materi mesin ESEC 3088. Pre-test akan diberikan setelah mahasiswa menonton motion graphic mesin ESEC 3088 untuk menilai tingkat pemahaman mahasiswa terhadap materi yang disampaikan. Pre-test dan post-test akan diberikan kepada mahasiswa kelas A dan B program studi Teknik Manufaktur Elektronika Reguler angkatan tahun 2019, pretest yang diberikan akan berjumlah 10 soal dan dilakukan melalui Google Form. Pertanyaan yang dilampirkan pada pre-test berjumlah 10 soal dengan jawaban pilihan ganda (multiple choice). Gambar 3 adalah alur pretest dan post-test.

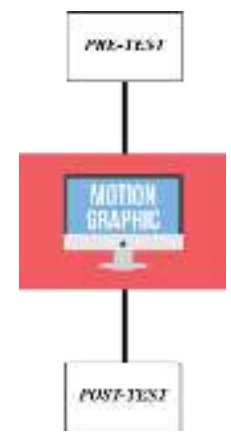

Gambar 3 Alur Pre-Test dan Post-Test

Menurut (Olis, 2013) proses penskoran terhadap pre-test dan post-test tanpa koreksi jawaban tebakan bisa dilakukan dengan menggunakan rumus penskoran. Gambar 4 merupakan rumus penskoran.

$$
\begin{aligned}
& \text { Skor }=\left[\frac{\left(\mathrm{B}-\frac{\mathrm{s}}{\mathrm{P}-1}\right)}{\mathrm{N}}\right] \times 100 \\
& \text { Gambar } 4 \text { Rumus Penskoran }
\end{aligned}
$$

Keterangan :

$\mathrm{A}=$ Skor

$\mathrm{B}=$ Jumlah item benar

$\mathrm{S}=$ Jumlah item salah

$\mathrm{N}=$ Jumlah item soal pilihan ganda

$\mathrm{P}=$ Jumlah pilihan (option)

$1=$ Bilangan tetap

Setelah itu, akan dicari nilai rata-rata dari hasil pre-test dan post-test untuk menilai hasil tingkat pemahaman mahasiswa antara pre-test dan post-test. Gambar 5 merupakan rumus cara menghitung nilai rata-rata (Caraharian.com, 2021).

$$
\text { Nilai rata }- \text { rata }=\frac{\text { Jumlah nilai }}{\text { Banyaknya data }}
$$

Gambar 5 Rumus Cara Menghitung Nilai Rata-Rata

Keterangan :

Jumlah Nilai $=$ Nilai yang didapat

Banyaknya Data = Jumlah Peserta (dalam 1 kelas)

Setelah didapat nilai rata-rata antara pre-test dan post-test, akan dibandingkan nilai rata-rata antara pre-test dan post-test. Jika nilai rata-rata post-test lebih tinggi dibandingkan nilai rata-rata pre-test, maka motion graphic yang dibuat oleh peneliti dapat meningkatkan tingkat pemahaman mahasiswa Teknik Elektro Manufaktur, 
begitu juga sebaliknya jika nilai rata-rata pre-test lebih tinggi dibandingkan nilai rata-rata post-test maka motion graphic yang dibuat oleh peneliti gagal untuk meningkatkan pemahaman mahasiswa.

\section{IMPLEMENTASI DAN PENGUJIAN}

Berdasarkan metode penelitian dan pengembangan multimedia dengan menggunakan metode Villamil-Molina dalam perancangan ini maka tahap berikutnya yang akan dijelaskan pada bab ini adalah tahap production, post production, dan delivery.

\subsection{Production}

Pada tahap produksi dilakukan pembuatan video profil motion graphic menggunakan software Adobe Photoshop CC 2019, Adobe Illustrator CC 2019, Adobe After Effect CC 2019, dan Adobe Premiere Pro 2019. Beberapa kegiatan yang dilakukan pada tahap production ini adalah tracing dan coloring, animating, dubbing, editing dan rendering sebagai berikut :

a. $\quad$ Tracing dan Rendering

Tahap tracing dan coloring ini menggunakan software Adobe Illustrator CC 2019. Tahap ini dilakukan untuk membuat objek-objek dasar yang nantinya akan digunakan sebagai bahan pada motion graphic ini. Tahap tracing dan coloring dapat dilihat pada tabel 3.

Tabel 3 Tracing dan Coloring

\begin{tabular}{|c|c|l|}
\hline No. & \multicolumn{1}{|c|}{ Gambar } & \multicolumn{1}{c|}{ Keterangan } \\
\hline 1. & & $\begin{array}{l}\text { Pertama yaitu masukan sketsa } \\
\text { gambar yang telah di scan berupa } \\
\text { gambar jpeg sebelumnya ke canvas } \\
\text { adobe illustrator. }\end{array}$ \\
\hline 2. & & $\begin{array}{l}\text { Kedua yaitu tracing semua objek } \\
\text { yang akan digunakan nantinya. } \\
\text { Tracing menggunakan Pen Tool } \\
\text { mengikuti sketsa awal yang telah di } \\
\text { scan. }\end{array}$ \\
\hline 3. & & $\begin{array}{l}\text { Setelah objek selesai di tracing tahap } \\
\text { selanjutnya yaitu tahap coloring atau } \\
\text { pewarnaan dengan klik pada bagian } \\
\text { yang ingin diberi warna. }\end{array}$ \\
\hline
\end{tabular}

Rincian beberapa objek, logo, icon, background yang sudah dilakukan tracing dan coloring. Hasil dari tracing dan coloring dapat dilihat pada tabel 4.

Tabel 4 Hasil Tracing dan Coloring

\begin{tabular}{|c|c|l|}
\hline No. & Gambar & \multicolumn{1}{|c|}{ Keterangan } \\
\hline 1. & & $\begin{array}{l}\text { Gambar ini merupakan hasil tracing dan } \\
\text { coloring pada peta negara Swiss. }\end{array}$ \\
\hline
\end{tabular}




\begin{tabular}{|c|c|c|}
\hline 2. & & $\begin{array}{l}\text { Gambar ini merupakan hasil tracing dan } \\
\text { coloring pada logo perusahaan ESEC. }\end{array}$ \\
\hline 3. & 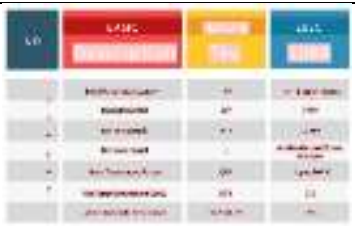 & $\begin{array}{l}\text { Gambar ini merupakan hasil tracing dan } \\
\text { coloring pada tabel/fitur mesin. }\end{array}$ \\
\hline 4. & & $\begin{array}{l}\text { Gambar ini merupakan hasil tracing dan } \\
\text { coloring pada thermometer suhu. }\end{array}$ \\
\hline 5. & & $\begin{array}{l}\text { Gambar ini merupakan hasil tracing dan } \\
\text { coloring monitor pada mesin. }\end{array}$ \\
\hline 6. & & $\begin{array}{l}\text { Gambar ini merupakan hasil tracing dan } \\
\text { coloring bond pad ke leadframe. }\end{array}$ \\
\hline 7. & ${ }_{4 \longleftarrow}^{2} \longrightarrow^{3}$ & $\begin{array}{l}\text { Gambar ini merupakan hasil tracing dan } \\
\text { coloring capillary. }\end{array}$ \\
\hline
\end{tabular}

\section{b. Dubbing}

Dubbing merupakan tahapan dilakukanya perekaman suara yang telah disesuaikan dengan narasi yang dibuat untuk menyampaikan informasi melalui video motion graphic Mesin ESEC 3088. Hasil dubbing yang telah dilakukan yaitu dengan format mp3. Hasil dari tahapan dubbing dapat dilihat pada gambar 6. 


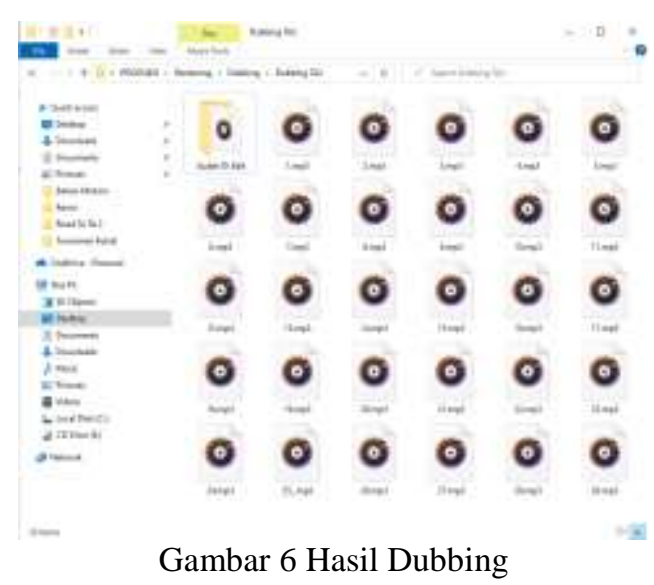

c. Animating

Pada tahap ini, dilakukan penggerakkan pada berbagai objek dengan memberi efek visual dengan mengubah scale, position, dan rotation disetiap objeknya, pada tahap ini juga dilakukan rendering untuk disetiap scene. Software yang digunakan pada tahap Animating ini yaitu Adobe After Effect CC 2019 dengan menggunakan plugin dan preset animation composer untuk membantu dalam menambahkan efek-efek tambahan. Proses animating dapat dilihat pada Gambar 7.

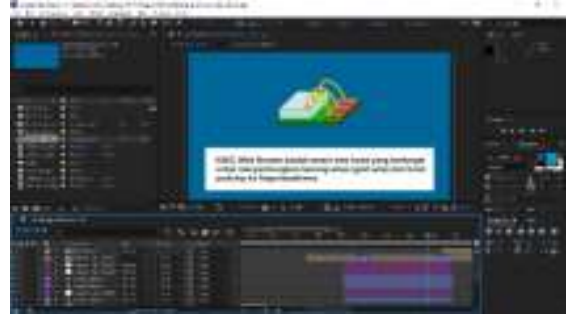

Gambar 7 Proses Animating

d. Editing

Setelah dilakukanya tahap animating maka selanjutnya dilakukan tahap editing. Tahap editing merupakan proses penggabungan hasil video yang telah di render sebelumnya pada Adobe After Effect CC 2019 yang kemudian hasil render dalam bentuk video tadi, harus di-edit agar video menjadi sempurna baik itu segi video maupun audio seperti dubbing, sound effect dan background music yang nantinya akan disajikan menjadi satu video. Tahap editing ini dilakukan di Adobe Premiere Pro 2019. Gambar 8 dibawah merupakan proses pada tahap editing.

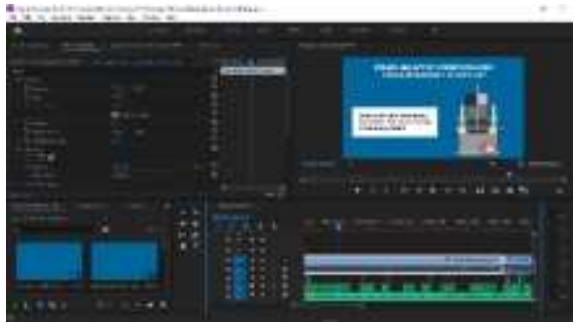

Gambar 8 Tahap Editing

e. Rendering

Setelah semua tahap telah selesai maka selanjutnya dilakukan tahap rendering. Rendering merupakan proses dimana semua scene pada video yang telah di edit, dan telah ditambahkan dubbing, sound effect dan background music digabungkan menjadi satu agar dapat menghasilkan sebuah file video dengan format mp4 dan aspek rasio 1080p. Tahapan rendering dapat dilihat pada Gambar 9. 


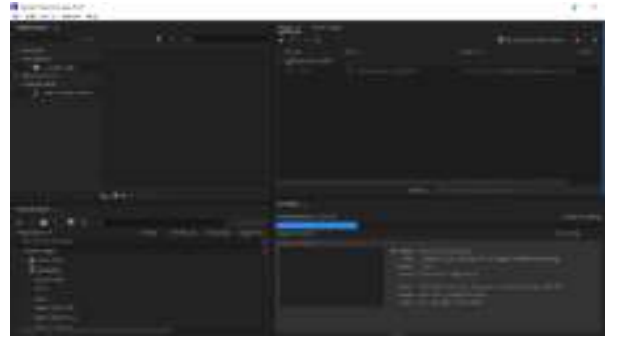

Gambar 9 Tahap Rendering

\subsection{Postproduction}

Pada tahap Postproduction ini akan dilakukan analisis terhadap video motion graphic yang telah dibuat oleh penulis dengan melakukan pengujian alpha testing dan beta testing bersarkan aspek-aspek yang terkait dan kemudian akan dilakukan analisis tingkat pemahaman mahasiswa terhadap materi yang disampaikan pada motion graphic yang dibuat.

\section{a. Alpha Testing}

Pada tahap alpha testing dilakukan pengecekan terhadap produk yang telah dirancang oleh penulis untuk ahli di bidang materi dan media, sehingga dapat diketahui kekurangan-kekurangan yang terdapat pada video bahkan saran yang harus di perbaiki kedepannya dalam proses pembuatan motion graphic ini. Pengujian ini dilakukan oleh validator materi dan validator media yang telah penulis tentukan. Pengujian dilakukan dengan mengisi kuesioner yang terdapat pertanyaan-pertanyaan yang telah di sesuaikan dengan video motion graphic yang telah di buat. Setelah itu dilakukan penghitungan presentase yang hasilnya akan didapatkan kesimpulan apakah setuju atau tidak terhadap kuesioner yang di ajukan dan kelayakan video motion graphic ini untuk ke tahap pengujian beta. Hasil dari perbandingan persentase aspek pada validator materi dan media dapat dilihat pada Tabel 5 dan 6.

Tabel 5 Perbandingan Persentase Aspek Pada Validator Materi

\begin{tabular}{|c|c|c|c|}
\hline No. & Aspek & Index & Persentase \\
\hline 1. & $\begin{array}{c}\text { Materi Mesin } \\
\text { ESEC 3088 }\end{array}$ & $910 / 11$ & $82,7 \%$ \\
\hline \multicolumn{2}{|c|}{ Jumlah } & $82,7 \%$ \\
\hline \multicolumn{2}{|c|}{ Rata-Rata Keseluruhan Persentase } & $82,7 \%$ \\
\hline
\end{tabular}

Tabel 6 Perbandingan Persentase Aspek Pada Validator Media

\begin{tabular}{|c|c|c|c|}
\hline No. & Aspek & Index & Persentase \\
\hline 1. & Objek Mesin & $180 / 2$ & $90 \%$ \\
\hline 2. & Teks & $250 / 3$ & $83,3 \%$ \\
\hline 3. & Warna & $230 / 3$ & $76,6 \%$ \\
\hline 4. & Gambar & $240 / 3$ & $80 \%$ \\
\hline 5. & Animasi & $240 / 3$ & $80 \%$ \\
\hline 6. & Suara & $150 / 2$ & $75 \% \%$ \\
\hline 7. & Video & $80 / 1$ & $80 \%$ \\
\hline
\end{tabular}




\begin{tabular}{|c|c|}
\hline Jumlah & $564,9 \%$ \\
\hline Rata-Rata Keseluruhan Persentase & $80,7 \%$ \\
\hline
\end{tabular}

Setelah mengetahui hasil persentase keseluruhan aspek yang didapatkan yaitu $82,7 \%$ pada validator materi, yang pada pengkategorian validasi menggunakan skala likert 1-5, mendapat kesimpulan bahwa motion graphic mesin ESEC 3088 ini dari segi aspek materi media pembelajaran berada dalam kategori Sangat Valid.

Pada validator media didapat nilai $80,7 \%$ yang pada pengkategorian validasi menggunakan skala likert 1-5, mendapat kesimpulan bahwa motion graphic mesin ESEC 3088 ini dari segi aspek kualitas tampilan media dan aspek daya tarik media pembelajaran berada dalam kategori Sangat Valid. Adapun mengenai saran-saran yang diberikan oleh validator materi dan validator media. Saran dari validator materi dan media dapat dilihat pada Tabel 7 dan 8 .

Tabel 7 Saran Validator Materi

\begin{tabular}{|c|c|l|}
\hline No. & Nama & \multicolumn{1}{c|}{ Saran } \\
\hline 1. & Mustanir, S.E & $\begin{array}{l}\text { Sangat keren dan bagus, saran untuk segera } \\
\text { dipublikasi. }\end{array}$ \\
\hline 2. & $\begin{array}{c}\text { Nur Sakinah Asaad, S.T., } \\
\text { M.T }\end{array}$ & $\begin{array}{l}\text { Pada scene menyalakan dan mematikan } \\
\text { mesin bahasanya masih campur antara } \\
\text { English dan bahasa Indonesia. }\end{array}$ \\
\hline
\end{tabular}

Tabel 8 Saran Validator Media

\begin{tabular}{|c|c|l|}
\hline No. & Nama & \multicolumn{1}{c|}{ Saran } \\
\hline 1. & $\begin{array}{c}\text { Budi Prio Utomo, Str., } \\
\text { Kom }\end{array}$ & $\begin{array}{l}\text { Drop shadow pada setiap objeknya saja } \\
\text { yang mesti dikurangin } \text { opacity nya. }\end{array}$ \\
\hline 2. & $\begin{array}{c}\text { Sandi Prasetyaningsih, } \\
\text { S.T., M.Media }\end{array}$ & $\begin{array}{l}\text { Voice over dan sound effect tumpang tindih } \\
\text { volumenya. (peak level diatur ulang). }\end{array}$ \\
\hline
\end{tabular}

b. Beta Testing

Setelah produk diuji oleh validator materi dan validator media, selanjutnya peneliti akan melakukan tahap beta testing dengan memberikan pre-test dan post-test kepada mahasiswa Teknik Elektronika Manufaktur untuk menganalisis tingkat pemahaman mahasiswa terhadap materi yang disampaikan pada motion graphic yang telah dibuat oleh peneliti dan menyebar kuisioner kepada masyarakat umum untuk menilai kekuatan aspek informasi, tampilan, dan pemahaman.

1. Pre-test dan Post-test

Pre-test dan post-test akan diberikan kepada mahasiswa Teknik Manufaktur Elektronika kelas A dan B regular pagi semester III Angkatan tahun 2020 Politeknik Negeri Batam. Soal pre-test dan post-test masing-masing berjumlah 10 soal, dengan tingkat kesulitan yang sama antara soal pre-test dan post-test. Setelah itu dilakukan penghitungan nilai rata-rata yang hasilnya akan didapatkan kesimpulan apakah motion graphic mesin ESEC 3088 yang dibuat oleh peneliti dapat meningkatkan pemahaman mahasiswa terhadap materi yang disampaikan. Jumlah mahasiswa kelas A regular pagi adalah 25 orang dan kelas B regular pagi adalah 27 orang. Hasil uji pre-test dapat dilihat pada tabel 9.

Tabel 9 Hasil Uji Pre-Test

\begin{tabular}{|c|c|c|c|}
\hline No. & $\begin{array}{c}\text { Rata-rata Nilai } \\
\text { Kelas A }\end{array}$ & $\begin{array}{c}\text { Rata-rata Nilai } \\
\text { Kelas B }\end{array}$ & Jumlah \\
\hline
\end{tabular}




\begin{tabular}{|c|c|c|c|}
\hline 1 & 32.8 & 36.4 & 69.2 \\
\hline \multicolumn{2}{|c|}{ Rata-Rata Keseluruhan Persentase } & $34.6 \%$ \\
\hline
\end{tabular}

Dari table diatas didapat hasil, kelas A regular pagi yang berjumlah 25 mahasiswa rata-rata mendapat nilai 32.8, dan kelas B regular pagi yang berjumlah 27 mahasiswa rata-rata mendapat nilai 36.4. Dan jumlah nilai kedua kelas tersebut adalah 69.2 yang mendapatkan hasil rata-rata keseluruhan persentase adalah $34.6 \%$. Perhitungan yang peneliti lakukan adalah sebagai berikut

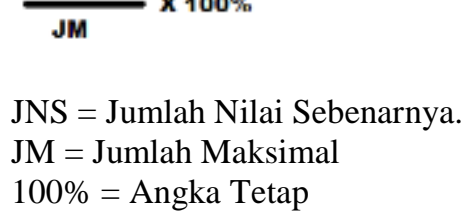

Setelah mahasiswa menjawab soal pre-test, mahasiwa akan menonton motion graphic yang telah dibuat oleh peneliti hingga selesai. Setelah menonton motion graphic mahasiswa akan menjawab soal post-test. Hasil uji pre-test dapat dilihat pada table 10.

Tabel 10 Hasil Uji Post-Test

\begin{tabular}{|c|c|c|c|}
\hline No. & $\begin{array}{c}\text { Rata-rata Nilai Kelas } \\
\text { A }\end{array}$ & $\begin{array}{c}\text { Rata-rata Nilai } \\
\text { Kelas B }\end{array}$ & Jumlah \\
\hline 1 & 59.6 & 59.5 & 119.1 \\
\hline \multicolumn{2}{|c|}{ Rata-Rata Keseluruhan Persentase } & $59.55 \%$ \\
\hline
\end{tabular}

Dari hasil uji pre-test dan post-test diatas didapat hasil, persentase uji pre-test kelas A dan B regular pagi adalah 34,6\% dan persentase uji post-test kelas A dan B regular pagi adalah 59,55\%. Dengan hasil persentase uji post-test yang lebih tinggi dibandingkan dengan persentase pre-test maka motion graphic mesin ESEC 3088 yang dibuat oleh peneliti berhasil meningkatkan pemahaman mahasiswa Teknik Manufaktur Elektronika Politeknik Negeri Batam terhadap materi yang disampaikan.

\subsection{Delivery}

Pada tahap delivery akan dilakukan proses pengemasan produk berupa video berformat mp4 dan aspek rasio 1080p dengan durasi 6 menit 37 detik yang dikemas dalam bentuk CD dan Cover CD. Lalu dilakukan publikasi produk melalui berbagai sosial media seperti youtube, facebook, instagram dan lainlain pada akun sosial media TFME. Sehingga video media pembelajaran berbasis motion graphic mesin ESEC 3088 akan mudah dicari dan dilihat oleh para mahasiswa dan dosen Politeknik Negeri Batam serta masyarakat umum. Desain CD dan case CD terdapat pada Gambar 10 dan 11.

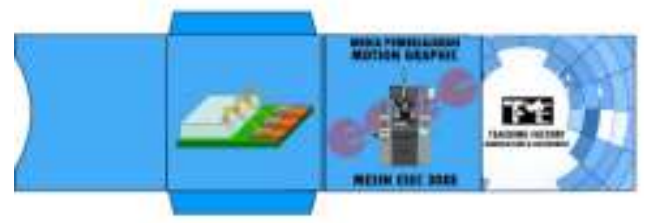

Gambar 10 Desain CD Label Motion Graphic Mesin ESEC 3088 
Gambar 11 Desain Case CD Motion Graphic Mesin ESEC 3088

\section{KESIMPULAN DAN SARAN}

1. Kesimpulan

a. Media pembelajaran mesin ESEC 3088 Wire Bonder berbasis motion graphic menggunakan metode Villamil-Molina dalam pembuatannya dengan hasil berupa video berdurasi 6 menit 37 detik yang berformat mp4 dengan aspek rasio 1080p.

b. Berdasarkan hasil uji pre-test dan post-test terhadap mahasiswa kelas regular A dan B pagi Teknik Manufatur Elektronika Politeknik Negeri Batam, yang menghasilkan nilai rata-rata post-test lebih tinggi dibandingkan dengan nilai rata-rata uji pre-test maka motion graphic mesin ESEC 3088 yang dibuat oleh penulis telah berhasil meningkatkan tingkat pemahaman mahasiswa terhadap materi yang disampaikan.

2. Saran

Saran bagi peneliti yang akan mengembangkan video media pembelajaran berbasis motion graphic selanjutnya yaitu dengan menggunakan perpaduan antara konsep videografi dan konsep motion graphic dengan konten yang lebih padat dan lengkap agar penonton dapat melihat dan memahami informasi secara keseluruhan baik itu ilustrasi yang disajikan pada konsep motion graphic maupun fakta yang disajikan pada konsep videografi pada media pembelajaran sekolah dasar, menengah, dan perguruan tinggi yang disajikan dalam satu video.

\section{DAFTAR PUSTAKAN}

[1] Caraharian.com. (2021). Cara Menghitung Nilai Rata-Rata Dengan Benar. (diakses pada tanggal 21 Juli 2021): https://caraharian.com/mencari-rata-rata.html.

[2] Lenterakecil. (2018). Pengertian Pendidikan Vokasi. https://lenterakecil.com/pengertian-pendidikanvokasi/: (diakses tanggal 22 Oktober 2020).

[3] Olis, K. (2013). Cara Menghitung Skor pilihan ganda (PG) Pada Soal Tes.

[4] Rudi, S., \& Cepi, R. (2008). Media Pembelajaran. Bandung: Jurusan Kurtekpend FIP UPI.

[5] Sukarno, I. S. (2008). Perancangan Motion Graphic Ilustratif Mengenai Majapahit Untuk PemudaPemudi. Bandung : Fakultas Seni Rupa dan Desain (FSRD) ITB. 